\title{
Expendable 'Written' ICT Policies in a Digital Era, No Broken Promise
}

\author{
Hüseyin Tolu ${ }^{a}$ \\ (a) PhD student at University of Bristol
}

DOI: 10.5033 /ifosslr.v5i2.86

\begin{abstract}
In Turkey, whether distinguishing software as Free Open Source Software (FOSS) or Proprietary Closed Source Software (PCSS), there is no precise 'National ICT Policy in Public Institutions.' It is crucial to evaluate ICT Policy, particularly how and why it is incomprehensible, as a case study to conceptualise ICT Policy from a national psyche. The study focuses on the reasons for not 'governing' ICT Policy and identifies the conditions behind this omission. I argue how FOSS is deliberately ignored due to: obvious, institutional inertia, path dependence and ungovernable ICT changes and, arguably, corruption in new public management. The study concludes that Turkey has failed to produce written ICT Policies and to establish pervasive and trustworthy (flexible) ICT ecosystems, which recognise either a balanced development between FOSS \& PCSS or a FOSS favourable system. Turkey has taken a de-facto ICT Policy, by which Microsoft dominant markets control public institutions. Whilst techno-institutional lock-ins politically exist and are irreversible, the future is mistakenly defined as a Procrustean ICT Bed Strategy. Globally, ICT Policy is understood to be an 'experimental strategy' (not definitive), perhaps for the purpose of ongoing negotiations and positioning of a national state within global networks because of evident nationally prioritised values and interests. Thus, the dynamic and failing nature of ICT ecosystems leads to 'no broken promise.'
\end{abstract}

\section{Keywords}

Un-Written ICT Policy; Free and Open Source Software; Corruption in New Public Management; a Procrustean ICT Bed Strategy; Governance 


\title{
Introduction
}

\author{
"In the age of information, ignorance is a choice." Donny Miller
}

Scholars distinguish software as Free Open Source Software (FOSS) and Proprietary Closed Source Software (PCSS) each of which has its own characteristic working properties and, not inevitably, the same rationale, breath and harmony, resulting in their own evolving strengths and weaknesses. The scope of this distinction is comprehensively argued in software literature; however, there are no compelling arguments to attempt conceptualising 'National ICT Policy' with or without hearing this crucial distinction in Turkey ${ }^{1}$. Explicitly, the literature argues under the title of 'ICT Strategy' or 'ICT Capability Strategy', rather than 'ICT Policy', indicating how the concept is globally challenged and the relevant conditions, in particular, formal and informal rules in public institutions, are neglected. Therefore, it is crucial to evaluate ICT Policy in Turkey, particularly how and why it is incomprehensible, as a case study to conceptualise ICT policy from a national perspective in a digital era.

The study focuses on the reasons for not governing ICT policy and the conditions that drive poor government intervention. I also extend the scope of this article to argue that FOSS is deliberately ignored in ICT projects due to obvious: (a) institutional inertia, (b) path dependence, (c) ungovernable ICT changes, and, arguably, (d) corruption in new public management (NPM). This study exposes the deliberate disregard of the above to conclude that Turkey has failed to produce written ICT Policies and to establish pervasive and trustworthy (flexible) ICT ecosystems which recognise either a balanced development between FOSS \& PCSS or a FOSS favourable system. The Government has taken a de-facto ICT Policy by which Microsoft dominant markets control public institutions. Whilst techno-institutional lock-ins politically exist and are irreversibly in Turkey, the future is mistakenly defined as requiring a Procrustean ICT Bed Strategy. Therefore, this study finally argues that ICT Policy in a national state is globally understood as using an 'experimental strategy' rather than 'definitive.'

Brief notes, in Turkey, we have had original Linux. The Scientific and Technological Research Council of Turkey (TUBITAK) has developed Pardus Operating Systems (OSs) (nationally distributed Linux distro) between 2003 and 2012. After ten years of Pardus development, the Pardus project has not achieved its initial or subsequent objectives as declared in 2004 \& 2011, and has mistakenly diverted away from those objectives to become Pardus Fraud-Debian, as Turkey's present day accepted open source software solution. Crucially, the Pardus project has been deliberately utilised as leverage to gain better ongoing deals from the Microsoft Corporation. So, Turkey has always aspired to Turkish Linux, however Turkey could not appreciate its opportunities. Nevertheless, Turkey has still FOSS communities, in particular for Pardus Original and Pardus Fraud-Debian ${ }^{2}$.

\section{Pardus made us salivate, but not eat!}

Considering the (previous) fact that the latest international reports show that FOSS is a real alternative to PCSS through global political-economic perspective, in Turkey, nonetheless, with the exception of the Ministry of Justice, software which has been developed by public institutions and/or private sectors, through supplying services methods, are not compatible with other OSs.

1 There is also a lack of academic argument in the concept of 'National ICT Policy'. See, Uckan, O. (2009). Weakness of National ICT Policy-Making Process in Turkey: The Governance Phobia, ICEGOV-International Conference on eGovernment and eGovernnace, 12-13 March 2009, Ankara-Turkey.

2 Pardus OSs Journey in Turkey is so argumentative due to the complexity of perceptions FOSS movements and philosophies, relationships and conflicts of FOSS communities, interventions from TUBITAK and the Government etc. The whole argument might be seen from FOSS communities in Turkey. There are so many detailed information shared by Pardus developers and academicians, e.g. Mustafa Akgul, Dr. Necdet Yücel, Doruk Fisek, Sezayi Yeniay, etc. All criticisms are recorded on the internet. 
This demonstrates that there are techno-institutional lock-ins within Turkey, particularly with Microsoft platforms (see, parliamentary written questions ${ }^{3}$ ). Notably, there is only one public institution, the Centre of High Performance Computing, that intentionally and solely relies on FOSS, 99\% (no Red Hat). Therefore, in Turkey, it is impossible to determine from the Government reports that there is a precise legal regulation in public institutions to incorporate FOSS. It is also true that there is no precise 'National ICT Policy' in Public Institutions (see, E-State: Concept and General Issues Report by the Prime Minister, June $2012^{4}$, and $25^{\text {th }}$ Meeting of the High Council of Science and Technology Report, January $2013^{5}$ ).

From a legal perspective, the law (policy) could be considered as; nothing is equal before legislation. However, when the concept is ICT, evidently legislation is not sufficient in order to counterbalance FOSS and PCSS, because

\section{'Between equal rights, force decides' Marx; \\ 'There is nothing more unequal than the equal treatment of unequals'}

From this point of view, why is Turkey a particularly good case study for investigating ICT policy? Turkey's centralised approach to ICT policy (de facto) and the expectation gap between its ambitions (to be global leader) and realisation (ongoing project failures) make it easier to identify where the issues lie. However, Turkey is not alone in failing to address ICT policy successfully; it is a global issue and locally, nations are getting it wrong. For instance, Marketshare (Market Share Statistics for Internet Technologies) state that in terms of market share in OS, Microsoft has $80.82 \%$, Apple has $7.02 \%$ and others $3.16 \%{ }^{6}$. There are similar claims, similar histories and the same outcomes in accepting the same (de-facto) ICT policy in many states. However, those states may have differing reasons for allowing themselves to be locked-in (controlled) by giant corporations.

\section{'He who controls the past controls the future. He who controls the present controls the past.' George Orwell}

\section{Methodology}

In the study, the data is obtained through documentary sources (only government reports and parliamentary written questions ${ }^{7}$ ). Notably, most provided documents are in Turkish. Therefore, it is not possible for the main target audiences to understand the original sources. So, further clarifications may be needed; for instance, are they official advices or regulations? In this study, the data is argued by employing a process tracing approach, which is

"The systematic examination of diagnostic evidence selected and analyzed in light of research questions and hypotheses posed by the investigator. Process tracing can

3 All parliamentary questions - over three hundreds- available from www.tbmm.gov.tr. Some parliamentary written questions from MP, Professor Dr. Alim Isik (08 ${ }^{\text {th }}$ March 2012, No:7/5313, $2^{\text {th }}$ March 2012, No:7/5228), MP, Isa Gok $\left(25^{\text {th }}\right.$ April 2008, No:7/2983), MP, Ayse Jale (24 ${ }^{\text {th }}$ January 2008 , No:7/1727), MP, Husnu Collu (24 January 2008 , No:7/1540), MP, Muharrem Toprak (24 ${ }^{\text {th }}$ February 2005, No:7/5052), MP, Emre Kocaoglu (23 $3^{\text {rd }}$ January 2002, No:7/5728), etc.

4 Prime Minister. (2012). E-State: Concept and General Issues Report, (E-Devlet: Kavram ve Genel Sorunlar); 2012, June 6, Retrieved 25/10/2013 from

http://www.tbmm.gov.tr/arastirma_komisyonlari/bilisim_internet/docs/sunumlar/Koordinasyon_Calismasi_Sunumea 06062012 1045.pdf.

5 Scientific and Technological Research Council of Turkey (TUBITAK). (2013) 25th Meeting of the High Council of Science and Technology Report; 2013, Retrieved 25/10/2013 from http://www.tubitak.gov.tr/sites/default/files/btyk25 yeni kararlar toplu.pdf.

6 More information from http://www.netmarketshare.com/operating-system-market-share.aspx?qprid=10\&qpcustomd=1

7 In this study, there are many translations (the author interpretations), particularly formal reports. Translation is squared brackets, and italic is for emphasising ([translation]). 
contribute decisively both to describing political and social phenomena and to evaluating causal claims" (Collier, 2011, p.823 ${ }^{8}$ ).

In using the process tracing approach, this study focused on interpreting the data by taking a picture of a range of particular movements in order to address/identify a series of interlinked phenomena, which cause and/or affect the outcome in this case-specific study. Many process tracing scholars (like historical scholars) aimed to clarify a particular historical outcome within a single-outcome study on the basis of sufficient and complete evidence through eclectic theorisation, as is the aim in this study. Process tracing is not really an evaluated and set related theory, unlike other research principles.

"The 'eclectic messy centre' should be clearer ... Neither theories nor cases are sacrosanct. Cases are always too complicated to vindicate a single theory, so scholars who work in this tradition are likely to draw on a mélange of theoretical traditions in hopes of gaining greater purchase on the cases they care about. At the same time, a compelling interpretation of a particular case is only interesting if it points to ways of understanding other cases as well" (Evans, 1995, p. $4^{9}$ ).

The purpose of this case-specific study is to

"uncover what stimuli the actors attend to; the decision process that makes use of these stimuli to arrive at decisions; the actual behaviour that then occurs; the effect of various institutional arrangements on attention, processing, and behaviour; and the effect of other variables of interest on attention, processing, and behaviour" (George and McKeown, 1985, p. $35^{10}$ ).

This study question is whether or not there is a (ongoing) precise 'National ICT Policy' in Public Institutions in Turkey and, in particular, an official recognition of the crucial distinction and subsequent evaluation between FOSS and PCSS?

\section{Lamenting FOSS in Turkey}

In Turkey, there is no precise 'National ICT Policy in Public Institutions' and thus no FOSS Policy Nonetheless, there are various evaluation reports in the use of FOSS, namely 'Short-Term Action Plan 2004 and 2005 Reports $^{11}$, '2006-2010 Action Plan for Information Society Strategy Reports $^{12}$, and over three hundred parliamentary written question responses during the years of 2005, 2008 and 2012.

Initially, No.3 Action Plan in 2004 emphasised that

[Many states in Europe, mainly Germany, have preferred to use open source software. EU standards and draft decisions submitted by the Global Information

8 Collier, D. (2012). Understanding Process Tracing, PS: Political Science and Politics, 44, No. 4 (2011): 823-30.

9 Kohli, A., Evans, P., Katzenstein, P. J., Przeworski, A., Rudolph, S. H., Scott, J. C., et al. (1995). The role of theory in comparative politics: A symposium. World Politics, 48(1), 1-49.

10 George, A.L. and McKeown T.J. (1985). Case Studies and Theories of Organizational Decision Making. Advances in Information Processing in Organizations 2: 21-58.

11 State Planning Organization Information Society Department. (2005). Short-Term Action Plan 2004 and 2005 Reports, Retrieved 25/10/2013 from

http://www.bilgitoplumu.gov.tr/Portal.aspx? value=UE9SVEFMSUQ9MSZQQUdFSUQ9MzYmUEFHRVZFUINJT049LTEmTU9ERT1QVUJMSVNIRURfVkVS U01PTg==.

12 State Planning Organization Information Society Department. (2006-2010). 2006-2010 Action Plan for Information Society Strategy Reports, Retrieved 25/10/2013 from http://www.bilgitoplumu.gov.tr/Portal.aspx?value=UEFHRU1EPTE2Jk1PREU9MQ== 
Society recommend using open source software. In particular, in e-government projects, they recommend software should not be closed source software] $\left(\mathrm{p} .13^{13}\right)$.

In the scope of E-Transformation Turkey Project (E-TTP) within the agreement of E-Europe+ Program (since 2003), No.7 Action Plan endeavoured to conduct an investigation to use FOSS in public institutions; it included all legislative, administrative and financial aspects. The accountability, under the headings of 'Feasibility Report', 'Migration Plan' and 'Pilot Study', was given to TUBITAK-UEKAE. Within one year, TUBITAK-UEKAE presented two comprehensive reports. The first, 'Viability of the Use of Open Source Software in State Institutions and Organizations ${ }^{14}$, instructs the migration process, providing global successful examples and recommending popular FOSS alternatives to PCSS. The second, 'Managerial, Financial and Juristic Dimensions of Open Source Software ${ }^{15}$, instructs government responsibilities and the importance of FOSS underlining two features: interoperability and accessibility/usability of data. The 'Feasibility Report' \& 'Migration Plan' studies recommended prioritising FOSS. The Pilot Study closed in its initial stage was abandoned in preference to the Information Society Strategy 2006-2010.

No.7 Action Plan also identified some of the major obstacles in the use of FOSS in public institutions, though this was not so comprehensive as to have included legal and legislative obstacles. Indications suggest that this could have been the result of a lack of nationalised ICT policy; there were three legal and technical criteria used in reasoning FOSS usage impractical.

[(1) Requiring warranty for software, (2) Required criteria in service network is not compliant with a FOSS supplier, and (3) Lack of written documents which are recognised by the current legislation to ensure that a FOSS supplier is the rightful owner of the software] (ibid, p.32)

TUBITAK defectively identified these three criteria to be manageable alongside 'judicial discretions' in administrations. This would suggest that the flexibility of 'judicial discretions' within the criteria conditions was mistakenly pursued. From legislative aspects, the conditions were:

[(1) The 'Law on Intellectual and Artistic Works' is shaped and designed through PCSS. Regularisation is needed (high risk). (2) The 'Public Procurement Law' has no legal obstacle, however, tender specification is shaped through PCSS and there is path dependence (medium risk). (3) In the 'Law of Mortgage', a written document is required for transferring financial rights, however, it cannot applied to FOSS low risk). (4) In the 'Consumer Protection Law', some public institutions require warranty, however, regarding consumer protection, it is not possible when the product is software (low risk). And (5) the 'Competition Act' has (no risk)] (ibid, p.33)

From administrative aspects, the conditions were:

13 State Planning Organization Information Society Department. (2004). No.3 Action-Plan in 2004, Retrieved 25/10/2013 from http://www.bilgitoplumu.gov.tr/Documents/1/KDEP/050300 Eylem03.pdf.

14 Scientific and Technological Research Council of Turkey (TUBITAK) - Informatics and Information Security Research Centre (UEKAE). (2005). Viability of the Use of Open Source Software in State Institution and Organization (Kamu Kurum ve Kuruluşlarında Açık Kaynak Kodlu Yazılımların Uygulanabilirliği), Retrieved 25/10/2013 from http://www.linux.org.tr/wp-content/uploads/2010/04/goc_kilavuzu.pdf.

15 Scientific and Technological Research Council of Turkey (TUBITAK) - Informatics and Information Security Research Centre (UEKAE). (2005). Managerial, Financial and Juristic Dimensions of Open Source Software (Açık kaynak kodlu yazılımların idari, mali ve hukuki boyutları), Retrieved 25/10/2013 from

http://linuxogrenmekistiyorum.com/wp-content/uploads/Eylem-7-rapor-1.pdf 
[(1) Continuing contracts: Decision-makers cannot play an active role in tenders, previous contracts and agreements to decide next steps (high risk). (2) The arbitrary behaviours of public administrators, as supporters of protectionism and disrupter's of innovation: Public ICT employees rarely achieve accolade for their success but, conversely, they are rarely held to account for their failures. These behaviours devastate innovative and creative mentalities in public personnel and institutions. Consequently, uninitiated employees quickly adopt public worker culture to conform and minimise risk, consistent with using PCSS accountable solutions only with PCSS accountable suppliers; 'the buck stops elsewhere'. If PCSS ICT projects fail, personnel in public institutions believe that they would be less accountable in the project evaluation process (high risk). (3) Software ownership: Administrators in public institutions desire to see owners of FOSS as a legal entity due to the habit of solving possible software problems within a single point. The culture discourages internal/public accountability of unsolvable software problems. Any insurmountable failure will be normalised and commoditised as business as usual. Therefore, accountability normally sits solely with the final decision-maker and project/programme owner (high risk). (4) Meeting needs: There are various products in ICT, and perception of products is shaped by needs and requirements. End-users historically have more experience of PCSS and their evaluation criteria are technopolitically biased towards PCSS; the evaluation criteria for FOSS is applied incorrectly and misunderstood, e.g. end-users evaluate FOSS without FOSS user experience, end-users apply supplier driven PCSS evaluation criteria to FOSS or end-users evaluate FOSS reality rather than FOSS potential (medium risk). (5) Awareness of example studies: There is little known case study precedent to encourage FOSS usage in public institutions. Where FOSS is used successfully within public institutions, there is also a high likelihood that it's operability and security will be highly sensitive, so highly confidential. The main impediment to FOSS usage is low confidence within the Government. Although some private sector suppliers also provide FOSS-based products, they do not clearly indicate/share widely due to the reluctance of their clients to encourage criticism re-risk (medium risk). (6) The uncertainty of future institutional software: Historically, software which has been developed by public institutions and/or the private sector has not always been, during its life-cycle, compatible with other OSs. There is an unreasonable belief that rewriting PCSS software for FOSS (or vice versa), to secure and compatible standards required, would be too resource hungry (medium risk). (7) The use of pirated software: Pirated software is a serious threat for FOSS development and implementation. There is common newspeak and misleading information about intellectual values in the public (low risk)] (p.36-37).

(Institutional inertia, path dependency and ungovernable ICT changes are clear.)

These three legal and technical criteria and legislative and administrative obstacles that make FOSS usage impracticable in public institutions, as argued in 2005. Crucially, the conditions have taken a turn for the worse, and are still in force.

Post 2005, No.74 Action Plan, 'the Use of Open Source Software in Public Institutions', within the scope of Information Society Strategy 2006-2010, endeavoured to conduct a feasibility study in a particular institution. Based on the principal of implementation outcomes, it was aimed at setting multiple FOSS migration models for all public institutions. TUBITAK-UEKAE introduced the promotion of cooperation studies. Unfortunately, three years later, in December 2009, TUBITAKUEKAE and the Energy Market Regulatory Authority (EPDK) signed a protocol to provide integrated information system solutions and so to implement FOSS migration. Meanwhile, TUBITAK declared several FOSS related projects, such as 'Collaborative Software Development 
Platform', 'Public Sector Linux Competency Centre (Linux Training)', 'Teacher Learning PardusLinux Protocol', etc.

However, all of these combined efforts have not achieved their initial and subsequent objectives, and resulted in failure. In the scope of the Information Society Strategy 2006-2010, five evaluation reports were published (from 2006 to 2010). The general discourse is that although the use of FOSS in Turkey is nearly as advanced as in many leading nations, there are some crucial obstacles. In public institutions, in particular, in E-TTP, FOSS products and usage are not encouraged. The main causes of this outcome are as No.7 Action Plan underlined in 2005. Consequently, available technologies have been platform dependent and shaped by 'non-standard ways'. The perceived urgent issue was that no available/precise 'National ICT Policy and Strategy Reports' resulted in no software and FOSS consideration. There are also uncertainties about accountability and responsibility in introducing and implementing ICT policy in Turkey.

These five evaluation reports repeatedly stated that performance measures are unclear and the plan does not yet exist. The last report (March, 2010) stated that 'the Use of Open Source Software in Public Institutions Project' is still in its start-up phase. After four years only $10 \%$ was completed.

[There was no progress made for intended studies, e.g., setting up a technical support system within TUBITAK and preparing training programs, and establishing a competence centre which carries out awareness, information, education, research, testing and certification in the use of open source software.] (ibid, p. $224^{16}$ )

\section{Expendable 'Written' ICT Policy}

It is clear that FOSS migration efforts have failed. However, the reasons for the failure of migration efforts are much more complex than the required legal and technical criteria and legislative and administrative obstacles, as argued in 2005.

There are always 'ICT Project Preparation Guides' (July 2005, August 2010, September 2011 and July $2012^{17}$ ) in the scope of E-TTP. The software chapter of the guides states that if software fulfils conditions and requirements of ICT projects, FOSS should be privileged \& prioritised in order to avoid technology dependent platforms. If software (1) clearly meets needs; (2) sustainability is not an issue; (3) there is a certification for favourable quality of product, or suppliers maturity; (4) searching harmony with ISO/IEL 15408 standards for information security; (5) if the terms and conditions are provided, national and open source software are privileged; (6) all source code and documentation (case tools, etc.) are taken by public institutions.

Despite the guides, there are crucial issues in the scope of E-TTP. The identified issues from the Prime Ministry Report (June 2012 ${ }^{18}$ ) might be grouped as: (1) Data sharing issues (breaking principles of interoperability reports, established legislations prevented data sharing and lack of privacy in personal data); (2) Software and system dependencies, particularly OSs; (3) Lack of coordination, communication and experience (poor coordination between investor institutions, lack of know-how concept in designing ICT projects, absence of directional consultancy services,

16 State Planning Organization Information Society Department. (2006-2010). 2006-2010 Action Plan for Information Society Strategy 2010 V Report, Retrieved 25/10/2013 from

http://www.bilgitoplumu.gov.tr/Documents/1/BT_Strateji/20100323_BTS_Degerlendirme_V.pdf

17 State Planning Organization Information Society Department. (2012). ICT Project Preparation Guides (July, 2012) (Kamu Bilgi ve İletişim Teknolojileri Projeleri Hazırlama Kılavuzu, Temmuz 2012), Retrieved 25/10/2013 from http://www.bilgitoplumu.gov.tr/Documents/1/Diger/Kamu_BIT_Projeleri_Hazirlama_Kilavuzu_2012_3.pdf.

18 Prime Minister. (2012). E-State: Concept and General Issues Report, (E-Devlet: Kavram ve Genel Sorunlar); 2012 , June 6, Retrieved 25/10/2013 from http://www.tbmm.gov.tr/arastirma komisyonlari/bilisim internet/docs/sunumlar/Koordinasyon Calismasi_Sunumea 06062012 1045.pdf. 
unprofessionally written tender specifications \& reports and delivery phases, and poor monitoring and evaluating); (4) Duplication of geographic information systems projects (mutual data standards are not coordinated, and even no communication with each other); (5) No national information security policy document (lack of technical support for information security, poor management and lack of coordination within/between public institutions regarding policy sharing); and (6) Protection of personal information (fear, uncertainty and doubt (FUD) factors). So, the Government documents provide evidence to state that there is no precise legal regulation in the use of ICT in public institutions by 2013 because of non-existent political interference. Although since 1983 TUBITAK has been responsible for identifying long term ICT policies and strategies based on the Law.77 (delegated legislation), TUBITAK has no political power to influence Ministries and the Government initiatives, resulting in no certain delivery and implementation of the ICT policy and strategy.

An example of a coordination issue is,

[Whilst establishing cable infrastructure between two cities, independent and uncoordinated projects were established, resulting in two separate and disjointed setting up lines between these two cities.] (ibid, p.7)

If the recommendations from the ICT Project Preparation Guides and the E-TTP issues from the Prime Minister are considered, the evidence indicates that there are some misconceptions within/between Ministries about what FOSS is. Is it possible to fully provide sustainability with FOSS products? Is it possible to certify all FOSS products? Naturally it is not, assuming accountability requirements. And how is it possible for an institution to decide on software through these recommendations? Is there any central public institution to provide appropriate support and documentation, even by 2013? No. The Government reports provide recommendations, but none of them are compatible and consistent with the FOSS ecosystem and potential.

Even though ICT Project Preparations Guides exist, they are not followed by public institutions. In response to parliamentary written questions, most Ministries could not give exact information about their software expenditures. The reason was clarified by the Prime Ministry/State Planning Organisations (SPO) in 2008. Based on the Law No.5018, 'Public Financial Management and Control Law', an investment proposal from public institutions is transmitted to the Undersecretariat of SPO, and then the 'Investment Program Preparation Guide' is taken as a basis to transmit the proposal for inclusion/exclusion. Software expenditures are also within this framework. Within ICT projects, hardware, software, consultancy etc. are included and are normally proposed as sub-components of the projects. This investment proposal was intended to detail far more than merely proposing to purchase software. Importantly, ICT projects included into 'Investment Programs' are not monitored through their sub-components; whole projects only are monitored. Naturally, there is no detailed information to identify sub-categories of ICT projects. Most purchased ICT products in Ministries are performed within open negotiation and/or direct purchasing in the frame of No.4734, 'Public Procurement Law'19.

SPO clarified the process of ICT related investments as above but, however, neglected other formal legislations. There are always circular letters from the Prime Ministry which translate as the 'Use of Licensed Software' $\left(06^{\text {th }}\right.$ February $1998^{20} \& 16^{\text {th }}$ July $\left.2008^{21}\right)$. The circular letters

19 Prime Ministry/State Planning Organisations (SPO), Turkish Grand National Assembly (08 $8^{\text {th }}$ May 2008, No.7/1917), Retrieved 25/10/2013 from http://www2.tbmm.gov.tr/d23/7/7-2983c.pdf.

20 Prime Minister/ Directorate General for Personnel and Principles. (1998). Use of Licensed Software, 16th July 2008, Retrieved 25/10/2013 from http://www.basbakanlik.gov.tr/genelge pdf/1998/1998-0320-01979.pdf.

21 Prime Minister/ Directorate General for Personnel and Principles. (2008). Use of Licensed Software, 16th July 2008, Retrieved 25/10/2013 from

http://www.basbakanlik.gov.tr/genelge_pdf/2008/2008-0010-006-08468.pdf 
structured (must be followed) purchasing computer software in public institutions.

[Budgeting: Prior to purchasing computer software, software and hardware must be specified as a separate item. When budgeting is prepared, licensing principles must be considered, number of needed software should be included in the budget.

Specification: In specifications, purchased computer software must be specified as a separate item, provided software must be licensed and cost of licences must be specified.

Delivery: In the temporary and final acceptance processes, for delivered software, it must be controlled as to whether or not software is licensed and only licensed software can be obtained.]

Evidently, public institutions have completed ICT investments and projects in contrary to 'Use of Licensed Software' instructions. The Prime Ministry itself has not been compliant in this regard. According to Law 3056 issued in 1984, the first duty of the Prime Minister is to ensure cooperation between the Ministries, to supervise the general policy of the Government, and to take necessary measure in order to fulfil the given services based on the Constitution and Laws. In this sense, any initiative perceived as inconsistent with the laws should be argued in the Ministerial Cabinet. However, there has no precedent case in the concept of this malpractice in Turkey. Crucially, there is no consideration of FOSS. Nevertheless, the operating norm of ICT-related projects and their purchasing processes also show institutional inertia and lack of version control management of ICT changes. Institutional economic exchanges occur through imperfect markets but, however, are barely coordinated by Ministries or the Government. From this point, the concept is exactly what Pierre Bourdieu argued.

"The left hand of the state has the sense that the right hand no longer knows, or, worse, no longer really wants to know what the left hand does. In any case, it does not want to pay for it. One of the main reasons for all these people's despair is that the state has withdrawn, or is withdrawing" (cited in Droit \& Ferenczi, 199222)

Regarding ICT and a national state, the evidence suggests that the concept goes beyond 'no longer knows' or 'really wants to know'. The concept is arguably more like 'Corruption in NPM'; indeed, it depends on how to define 'corruption'. According to Williams $\left(1999^{23}\right)$, "corruption is complex and multifaceted and resists simple labelling. How corruption is defined depends on the context in which it is located; the perspectives of the definers and their purpose in defining it" (p.512). As a general term, McCormack $\left(1997^{24}\right)$ identified corruption, on the part of a normal assignment of public officers, by reason of 'pecuniary' or 'status gains'. Corruption occurs 'behind the screen', and is not readily brought to light; in particular, 'petty corruption' at lower duties and 'grand corruption' at higher duties.

The latest reports shows that ICT contributes towards fighting corruption with NPM: (1) monitors public employees' corrupt behaviours and practises, (2) introduces a new solution to curb/mitigate corruption, (3) illustrates anti-corruption efforts with transparency of procurement systems, (4) improves the quality of public services, and (5) reduces the level of corruption (see

22 Droit R.P. and Ferenczi, T. (1992). The Left Hand and the Right Hand of the State, interviewed with Pierre Bourdieu, Retrieved 25/10/2013 from http://www.variant.org.uk/32texts/bourdieu32.html.

23 Williams, R. (1999). New Concept for Old? Third World Quarterly, 20 (3) June, 503-13

24 McCormack, R. (1997). International Corruption: A global concern. Paper presented to the International Anticorruption conference, Peru, 1997. 
Proskuryakova et al., 201125; Shim \& Eom, 200926, etc.). However, ICT also creates uncertainties and incompleteness in accountability processes (managerial, political, financial and public accountabilities in NPM). Is the portfolio management of the ICT landscape clear? Is ICT strengthening governance with public or private sector interests, or both? Are ICT suppliers really positioning themselves inside and/or outside in NPM? Or more likely, are ICT suppliers within a fragmented network? Is there any clearly identified accountability? In this sense, ICT may have a positive and negative impact on socio-economic capital. So, many of these actions introduce not just technological changes, but changes of the operating culture of governing within a government.

The Government reports provide evidence that Ministries and the Government have favoured PCSS products and they are techno-politically biased towards PCSS in ICT projects, as argued later in the article. When the Government stated that there are coordination issues, the evidence suggests that many of these can be attributed to corruption. There is evidence to state that these coordination issues have been identified by different parts of state apparatus, highlighted as to be urgently rectified, yet the Government has not taken any initiative to address these issues by 2013 . These issues continue deliberately, through covert lobbying ${ }^{27}$, abusing the failings of an imperfect market only likely to become more clandestine and sophisticated in future due to mainly 'knowwho' and 'trust' concepts. Nevertheless, in reality, it is extremely difficult to prove 'corruption' versus 'coordination', however, evidence of techno-politically protected failed ICT projects are too numerous to ignore.

The concept of 'corruption in NPM' may also be interlinked with the consideration of 'Governance Models' in identifying how the Government in Turkey has been acting in the digital era, whether it is 'Cooperative Governance' as declared by the Government since 2005 or other governance models (e.g. Anglo-Governance, Polycentric Governance etc,). Nonetheless, what is clear is that,

"Politically protected monopoly rents are at the heart of profitability in the most advanced sectors of the global neo-liberal economy. Profitability for everyone from Big Pharma and their proprietary drugs to Microsoft and its monopoly on Windows depends on gaining and maintaining monopoly control over intangible assets, which can be achieved only by political means" (Evans, 2008, p.278 ${ }^{28}$ ).

Michael Tiemann, who is the President of 'Open Source Initiative' and the Vice President of 'Open Source Affairs' in Red Hat in 2010, stated that although there is a strong growing global FOSS economy, "more than \$500 USD IT spend is wasted; $18 \%$ of all IT projects abandoned before production; 55\% of all IT projects "challenged" (late, broken, or both)." "Proprietary software model destroyed $85 \%$ of the global innovation potential." ${ }^{29}$ The current argument in the UK Parliament is under the title of 'tech-light budget ${ }^{30}$. Importantly, Savage (2010) earlier

25 Proskuryakova, L., Abdrakhmanova, G., and Pitlik, H. (2013). Public Sector E-Innovations: E-Government and Its Impact on Corruption, Basic Research Program, Working Papers, Series: Science, Technology, Innovation, Higher School of Economics Research Paper, No. WP BRP 04/STI/2013, Retrieved 25/10/2013 from http://papers.ssrn.com/sol3/papers.cfm?abstract id=2206964.

26 Shim, D.C. and Eom, T.H. (2009). Anticorruption effects of information communication and technology (ICT) and social capital, International Review of Administrative Sciences 2009 75: 99.

27 It is more ambiguous, because Turkey has no clear lobbying regulation, and is defined as 'No Statutory Rules' by Chari, R., Hogan, J., Murphy, G. (2010) Regulating Lobbying: a Global Comparision. Manchester: Manchester University Press. See more, the lobbying global regulations from http://regulatelobbying.com/index.html and also, in more specific, it can be seen at the Lobbying Disclosure Act Database in the United States Senate from http://soprweb.senate.gov/index.cfm?event=selectfields, see registrant name as Google, Microsoft, and Apple etc. Turkey as many other leading \& led nations, has no disclosure regulation as specified as in the USA.

28 Evans, P. (2008). Is an Alternative Globalization Possible? Politics Society; 36; 271,

29 Tiemann, C. (2010). Growing an Open Source Economy With Competence at the Centre, Open Source Initiative Vice President, Open Source Affairs, Red Hat Inc.

30 See, IT industry slams chancellor's "tech-light" Budget, Retrieved 25/10/2013 from http://www.computerweekly.com/news/2240179870/IT-industry-slams-chancellors-tech-light-Budget. 
remarked in the independent that

"The total cost of Labour's 10 most notorious IT failures" (£26bn) "is equivalent to more than half of the budget for Britain's schools last year. Parliament's spending watchdog has described the projects as "fundamentally flawed" and blamed ministers for "stupendous incompetence" in managing them." ... IT experts blamed ministers for being too easily wooed by suppliers. Insiders said a lack of expertise within the Government about the technology industry meant they were willing to believe claims made by major IT firms before contracts were awarded." ${ }^{31}$

This situation was replicated in Turkey, e.g. the Pardus project (abandoned by TUBITAK- over 17.5 Million TL), Eskisehir Software Base Young Entrepreneur Training Centre (1 Million TL lost ${ }^{32}$ ), ILSIS system delay, etc. An example of a failed project is the 'Institutional Source Planning Project' in the scope of the 'Digital Recording Archive and Analysis System (SKAAS) Project'. It aimed to gather all Radio and Television High Council databases in a particular system and to make a secure digital document circulation system. The responsibility was given to the General Directorate of State Supply Office (DMO) in 2007. DMO designed the tender within 36 weeks. Due to project incompletion, the tender supplier incumbent was given a project extension of 15 weeks. In the project, there were two main components: (1) hardware and license and (2) software. Hardware and license were provided to the DMO HQ. The software system analysis and design reports were delivered, but multiple other deliverables were not completed / provided. Although the company requested another extension, DMO decided to cancel the project. The Supervisory Board launched an investigation, and found that the project was 'improvidently' coordinated ${ }^{33}$. In other words, 4.3 Million TL lost. In ICT projects,

"The governance network and policy network analysis schools both share the view that ... policymaking is best seen as an interactive process in which different actors exchange resources in a series of trust-based relationships in order to achieve their goals." (Daugbjerg, 2011, p. $4^{34}$ )

An interactive process can be argued from Cowan \& Gunby $\left(1996^{35}\right)$ perspectives. They proposed three main forces: 'technology externalities' (resulting in excess inertia - more agents use it), 'learning curve' ('learning by using' and 'learning by doing' as a snow-balling effect) and 'uncertainty reduction' (perceived benefits/risks of switching to a new technology); these all resulted in positive feedback, which all share three features: 'path dependence', 'inflexibility' and 'potential regret'.

In Turkey there is both clear technological path dependency and institutional inertia, but these arguments make us think institutionally as to how the policy influences dependencies and inertia. North $\left(1990^{36}\right)$ stated that "institutions are the rules of the game in a society, or more formally, are the humanly devised constraints that shape human interaction. In consequence, they structure incentives in human exchange, whether political, social, or economic"; it reduces "uncertainty by

31 Savage, M. (2010). Labour's computer blunders cost £26bn, 2010, Retrieved 25/10/2013 from http://www.independent.co.uk/news/uk/politics/labours-computer-blunders-cost-16326bn-1871967.html

32 Prime Ministry/State Planning Organisations (SPO), Turkish Grand National Assembly (08 ${ }^{\text {th }}$ October 2008 , No.7/10155), Retrieved 25/10/2013 from http://www.tbmm.gov.tr/develop/owa/yazili_sozlu_soru gd.onerge bilgileri? kanunlar sira no $=77722$

33 Ministry of State, Turkish Grand National Assembly (23 ${ }^{\text {rd }}$ March 2011, No. 7/18884), Retrieved 25/10/2013 from http://www.tbmm.gov.tr/develop/owa/yazili sozlu soru gd.onerge bilgileri?kanunlar sira no=89789

34 Daugbjerg, C. (2011). Governance Theory And The Question of Power: Lesson Drawing from The Governance Network Analysis Schools, Paper to the 61st Political Studies Association Annual Conference, 19-21 April 2011, London. Panel: Governance Networks and Policy Outcomes.

35 Cowan, R. and Gunby, P. (1996). Sprayed to Death: Path Dependence, Lock-In and Pest. Control Strategies. The Economic Journal 5 (106): 521-42.

36 North, D.C. (1990). Institutional Change, and Economic Performance, Cambridge: Cambridge University Press. 
providing a structure to everyday life" (p.3). So "institutions define and limit the set of choices of individuals" (p.4). There are three main concepts: 'the rules of the game', 'humanly devised constraints' and 'shape human interaction', and all these result in individuals and institutions shaping each other. There are 'formal written rules' (explicit enforcements from state, e.g. political, judiciary and economical rules and contracts, 'often devised with private (rather than social) benefits in mind, so the actual structure of rules will reflect the relative bargaining power of different parties') (p.47) and 'unwritten codes of conduct' (implicit interpretations of actors from formal rules because there is no formal enforcement by state as 'transmitted information and are a part of the heritage' that is called 'culture' or 'commitment') (p.37). North further argued that "we need to know much more about" (informal rules) and "how they interact with formal rules" (p.140) to understand the shift from governing behaviour rules to actual acting behaviours. Greif $\left(2006^{37}\right)$ stated that "an institution is a system of rules, beliefs, norms and organizations that together generate a regularity of (social) behaviour" (p.30). According to Greif, these elements (rules, beliefs, norms, organisations and regularities) are 'equally ambiguous concepts' because there might be formal rules which are not as effective as informal rules, or vice versa. The study argues that formal and informal rules are not directly distinguishable in relation to their powers in ICT projects, because formal rules are interpreted from actors' subjective perceptions and, thus, informal rules simply exist through actors understanding. Informal rules (culture) is the binder for the practices with obeying/ignoring formal rules that causes us to think that there is beyond 'no longer knows' or 'really wants to know' concepts, but arguably 'corruption in NPM'.

In Turkey, Justice and Development Party (AKP) has been the compelling Government since 2002, so all these reports represent AKP's political and social perspective regarding FOSS. Contrary to popular opinion, in a thoroughly pliable media, the parliamentary reports demonstrate that not all Ministries promote FOSS and Linux OSs; some of them clearly criticise FOSS and discount FOSS philosophies in terms of economical perspectives. Although there is no particular coherence in Ministries' behaviours regarding ICT when a culmination of these reports is taken into account, the Government has taken pragmatic decision strategies within a global political economy without examining ICT changes and its intellectual history, and have carelessly neglected the importance of FOSS, e.g. in 2008, the Ministry of Environment and Forestry stated,

[Applications in Linux Ecosystem are still in the development process. Eliciting so much effort and then granting all these as a public good-GPL are still in continual dispute] $\left(\mathrm{p} .83^{38}\right)$

A cynical response to the Ministry would be that FOSS developers look like penguins; they are pretty wealthy, just see Richard Stallman! It is necessary for successful computer scientists to start by being a FOSS developer.

Notably, in response to parliamentary written questions, some Ministries have preferred to provide misinformation and disinformation to the parliament instead of giving accurate and unbiased information and so accepting path dependencies and vendor lock-in issues, particularly Microsoft and Oracle products, e.g. The Ministry of National Education (MoNE) impenetrably disavowed the lock-in issue to the Internet Explorer in MEBBIS system, which is an educational portal for Turkey, ${ }^{39}$ and claimed that MEBBIS was designed based on open source software and Pardus-Linux OS is not compatible with this kind of infrastructure.

For Ministries, what are the consequences or sanctions of misinforming and disinforming the

37 Greif, A. (2006). Institutions and the Path to the Modern Economy, Cambridge: Cambridge University Press.

38 Ministry of Environment and Forestry. (2008) Turkish Grand National Assembly; 2008, March 13, No: 7/0727, Retrieved 25/10/2013 from http://www2.tbmm.gov.tr/d23/7/7-1727c.pdf

39 Ministry of National Education, Turkish Grand National Assembly (No. 7/1727, 24 ${ }^{\text {th }}$ January 2008), Retrieved 25/10/2013 from http://www.tbmm.gov.tr/develop/owa/yazili_sozlu_soru gd.onerge bilgileri? kanunlar_sira no $=60399$. 
parliament? Unfortunately, the 'Constitutional Law' in Turkey does not contain or clarify any information on this issue. Nevertheless, in accordance with the Law No.99, 'the Internal Regulation of Grand National Assembly of Turkey (TBMM)', a parliamentary written question is sent to the Prime Minister or related Ministry, requiring an answer within fifteen days. If a response is considered inadequate, MPs have a right to speak in parliament, without exceeding five minutes, to challenge the response. The proficiency of the speaker determines the exposure of the responses accuracy and robustness; this is a common method of objection in Turkey, but not always effective. Consequently, there is no requirement to take political responsibility because there is no penal or legal sanctions. The government, ideally, relies on the independent separation of legislature, judiciary and executive powers, however, the concept of parliamentary written questions is a political pathing (path-control) and its sanction is only political. In an ideal scenario, the Government and Ministries lose confidence in the parliament on this question. If $66 \%$ of parliament feels further investigation into the question is required, then an interpellation for the relevant Ministry or the Government takes place; this has no precedent in the concept of ICT. In regards to software, the disinformation / misinformation provided by Ministries have been perceived as either inconsequential or too difficult to pursue. This difficulty to account further supports the potential opportunity and breadth for 'corruption in NPM' in the digital era.

All responses to parliamentary written questions are significantly detailed; therefore, this study has chronologically prioritised both the salient points that Ministries raised and where they divert from No.7 Action Plan of 2005. In the early stages, in 2008, Ministries stated that OS is a specialisation study because of its complexity, but the same complex technical service and support has not been reflected in software developed by volunteers. 800,000 companies across the world and 7,000 companies in Turkey provide Microsoft products support. In each city and in each district, there is one Microsoft business partner who can provide technical support. In comparison, 'Linux World' support is based on 'volunteers' alone; though this perception is misleading as it would suggest by 'volunteers' that the FOSS ecosystem support strength is underestimated. By many, it is!

As SPO earlier concluded that

[Making regulation for the use of Linux OSs (particularly Pardus) as imperative in all public institutions is not considered in a short period because it is evaluated as nonenforceable]. $\left(2008, \mathrm{p} .4^{40}\right)$

Making regulation was considered unenforceable. However, after four years, the concept has shifted to a different direction; stakeholders have realised that the nature of mandatory policy restricts effective development, whilst Ministries have met with Linux. Within initial interactions, Ministries highlighted various technical issues and criticisms with the 'Linux Ecosystem', without evaluating/criticising their institutional structures in relation to ICT. The Ministries' criticisms are not logical, truthful and professional, e.g. Linux OSs do not support software used in institutions, but institutions can ensure that software is written OS-Agnostically ('write once/run anywhere').

To explain in simple terms, the crucial mistake is that the Ministries expected Linux to be a clone/mirror of Microsoft Windows; however, Linux is Linux and should not be perceived or evaluated in that way. Additionally, the overall attitude of Ministries upon ICT is;

"'If your attitude to IT is 'Who do I sue when things go wrong?' the document concludes, then perhaps OSS is not for you" (IDA, 2003 ${ }^{41}$ )

40 Prime Ministry/State Planning Organisations (SPO), Turkish Grand National Assembly (No.7/2983, $9^{\text {th }}$ April 2008), Retrieved 25/10/2013 from http://www.tbmm.gov.tr/develop/owa/yazili sozlu soru gd.onerge bilgileri? kanunlar_sira no $=63688$

41 International Development Association (IDA) (2003). Open Source Migration Guidelines, Retrieved 25/10/2013 from http://ec.europa.eu/idabc/en/document/1921.html. 
In 2012, the Ministry of European Union attempted refuting the argument of FOSS and PCSS distinction, through publicly commenting on (1) the essential technological knowledge and skill in public institutions and (2) positive feedback of being kept in institutional inertia (i.e. uninterrupted service provision). These two realities might be casuistry logical but "a decision can be rational without being right and right without being rational" (Peterson, 2009, p. $4^{42}$ ). However, the Ministry totally dismissed the case and accused MPs, who respectfully submitted the parliamentary written questions, of being too naive to understand ICT reality and politically and apathetically were ignoring the Government efforts. The Ministry stated that end-users possess only PCSS platforms knowledge and skill, in particular Microsoft Oss, that restrict seeking solutions outside of these available ICT parameters within public institutions. When the concepts of (1) end-users' reluctance to change and so their rejection due to their vested skill, and (2) their average age are considered, initially end-users should be persuaded to use Linux OSs at work as additional in-service training. The Ministry believes 'voluntary migration processes' should be utilised to obtain user buy-in. The Ministries' generic argument shows a fear of migrating to Linux OSs and, as a result, being suddenly ignorant of ICT. Their arguments neglect to account for consideration of 'knowledge transferring effect', 'de-learning effect', etc. The literature of technology in society argues that the key concept is how to be a 'Digital Naive' from a 'Digital Alien', not to be a 'Windows Naive'. Admittedly, the concept of 'digital literacy' entails, as its very name implies, 'digital', so the concept is to be possessed of 'a lifelong learning of technology', not just to be knowledgeable of 'skills of particular ICT applications'. The key issue is 'human resources-specific management' within national and international lobbying activities rather than technology-specific visibilities.

In this sense, the Ministries' 'voluntary migration' approach of needing buy-in for FOSS acceptance is misleading because 'modern' history shows that when governments put a law into force, society obeys, e.g. in the scope of the E-TTP project, nearly all public institutional services have been digitalised but none on a voluntary basis. Is MEBBIS voluntary for teachers and students? No! Using Standard Turkish F-Keyboard is obligatory in the MoNE since 2001 (No.1817). Is F-keyboard voluntary-based? No. So, either:

(a) The Government attempted to make initiatives imperative, rather than voluntary, if they thought they could get away with it if it was deemed an important priority / internationally accepted, or

(b) The Government attempted to normalise their contributions towards ICT policy deployment failure, or

(c) Both

The evidence shows that it is both, as imperative ICT regulations and judicial legitimacy in public institutions are also neglected and ironically suffering (they are aware of this). Regulations are not followed by public institutions, such as interoperability framework guides, F-keyboard regulation, etc. Obviously, some formal rules have become ineffective due to neglecting the influence of informal rules and other perceivable and unperceivable effects, such as Network Effect (applications barrier to entry), Indirect Exclusionary Effect (actually a design choice), Fashion affect of 'new' technology, etc.

From the arguments of voluntary migration and ineffective ICT formal rules, it is clear that Ministries have provided their disingenuous support for FOSS with an emblematic amount of (failed) FOSS investment. What makes this interesting is that some Ministries jejunely stated that the pool of developed applications for Linux ecosystem are not broad enough in comparison with the current system they use, and Linux ecosystem is not widespread globally. These are the main reasons given for not using Linux OSs. If Linux OSs are to become a common OS and developed applications are to become compatible with Linux OSs, there is no obstacle to migrating to Linux

42 Peterson, M. (2009). An Introduction to Decision Theory, Cambridge University Press 
OSs. The discourse of Ministries emphasized one reality (uncommon OSs) in the Linux ecosystem; however, they have deliberately neglected the main responsibility of the Government and their contributions for this outcome; in particular, their tender specifications reports, ICT policies and strategies, etc. Indications suggest the efforts to normalise (diminish) their contribution to this failure. In this sense, Ministries have pursued Linux to be Windows and, thus, are inadvertently a Microsoft spokesman, though the concept is much more complicated than that, as argued in the final section.

Besides all these imperfections, most Ministries stated that 'the best', 'the most reliable' products with 'the best price' are chosen for their ICT projects. The Ministries feel an obligation to provide 'uninterrupted service to 74 million citizens' and give this priority as their motivation, but their decision making is overly risk averse. This perspective is controversially arguable through technological comparative studies between FOSS and PCSS; and Linux OSs and Windows OSs. We can simply ask how Ministries, based on Microsoft platforms, provide their services successfully; e.g. MEBBIS crashed, so could not be assigned to teachers (2012); e-school totally crashed; teachers were not able to provide students grades, school reports were at risk, unable to input school data (2010) etc. Thus, purchasing products and taking technical services and support through the best, the most reliable and the best price (for them) are clearly not a guarantee for providing uninterrupted services for Ministries. Fundamentally, ICT culture should be,

"Today's technological transformations hinge on each country's ability to unleash the creativity of its people, enabling them to understand and master technology, to INNOVATE and to ADAPT technology to their own needs and opportunities" (UNDP Human Development Report, 2001, p.7933)

\section{The Future- a Procrustean ICT Bed Strategy}

The above imperfections, discussed in the ' $25^{\text {th }}$ Meeting of the High Council of Science and Technology', held at TUBITAK on $15^{\text {th }}$ January 2013 , with the purpose of evaluating emerging developments and identifying a new Turkey roadmap, included the following concerns;

[to complete 'Ex-Ante Impact Assessment of 'Horizon 2020: the EU Framework Programme for Research and Innovation' for Turkey' (which is an assessment forecast to identify actual and potential 'scientific', 'economic/industrial' and 'societal' impacts of an intervention in the processes of planning, designing and approving interventions through considering economic, social and environmental actors and factors);

to establish new 'Working Groups' that facilitate the coordination within TUBITAK to identify National ICT System and Performance;

to establish E-transformation Organisation Management Models for coordination issues within/between institutions (an agent from each institution for a technical consultancy unit);

to establish the Procurement Service Company Certification System for the E-TTP (in particular, for software suppliers, (so crucial for FOSS) but there was no information, no defined benchmarking and no performance measurement. This looks like a blueprint program but it is unclear at this point);

43 United Nations. (2001). Human Development Report, Retrieved 23/04/2011 from http://hdr.undp.org/en/reports/global/hdr2001/chapters/. 
to establish Package Software Solutions Supply Volume Method required by public institutions (creating package software inventory, and for bulk purchases as technical, legal, administrative and application model developments. Most institutions have been using the same software products, and so it is necessary to purchase them in bulk under one roof (owner) for retrenchment and avoiding wastage, in particular package software (office, database, etc.,), common systems (electronic data processing systems, in-service education, document management systems, and geographic information systems for local services);

(This initiative is the same as in the UK, (see, the report of ICT Strategy by Cabinet Office, p.13-Action $2^{44}$ ). For the UK, Action 4 is to establish an open source implementation group. For Turkey, there is no such thing in existence or planned, just FOSS recommendations.)

to start feasibility study for National Data Centre Structure (as in South Korea) (as argued above, it previously failed - SKAAS project)]

The ICT Strategies in Turkey and in the UK have the purpose of increasing accountability in public and private sectors and improving the participation of the private sector, within public sectors, through encouraging the SMEs. In an expensive and fragmented ICT infrastructure (generally in the duplicated solutions that impede reuse of services and sharing), the declaration is that 'common and secure application solutions, strategies and policies' will be taken through (again) 'common technology standards and components', as the reports highlighted that the concept of 'commonality' will be used in Turkey and in the UK. However, there is no clear statement to explain what is really meant by the statement of "commonality of standards and components'; is it a dominant orientation of ICT governance? Is that horizontally coordinated and balanced between FOSS and PCSS by multi-stakeholders agreements? Is the paradigm still in centralist stagnation by vertical/hierarchical decision imperfection? Where is 'policy interactionclustering' to define the same target from different actors' interests and values? Where is (inter/intra) industry-academy cooperation as strategic alliances/counterparts? Is there a social contract or a systematically changed strategy? Or are there 'Black Holes'? Nonetheless, it is clear that the ICT Strategy Report is a kind of declaration of intended future steps; the actual practices depend on the strength of non-uniformity.

Regarding software, the declared strategy, in particular 'commonality', actually is 'One-Size-FitsAll-Software' as a Procrustean bed. Nevertheless, a one-size-fits-all software system cannot be adapted to ICT nature, even within a short period of time and is not the most productive and persuasive solution in ICT. The various needs of a nation state, current and future, cannot be adjusted to one-size-fits-all; ICT is naturally borderless and unmanageable; different software may work better in different settings, and there are always vendor lock-in issues, etc. Importantly, FOSS cannot (might not, shall not, etc., depending on contents) be a tailored one-size-fits-all system. Consequently, the Government in Turkey has already put FOSS alternatives out of Turkey's future reach, lost any ability to gain FOSS opportunities, and critically and significantly narrowed the potential for Turkey. So what might be the actual reasoning for this outcome?

Due to emerging technologies, throughout history, communication channels and public and private sector services have all been digitalised. Nowadays, all performed services, in any institution, totally depend on ICT. The infrastructure of ICT in institutions is formed by various components, which are integrated to be compatibly working together. Software, in particular OSs, is the fundamental backbone in these components, and it is crucial. For this reason, available personal computers used in institutions have become no longer a stand-alone system. Institutional

44 Cabinet Office (2010). UK government ICT Strategy resources, Retrieved 25/10/2013 from https://www.gov.uk/government/publications/uk-government-ict-strategy-resources. 
requirements (ICT security, network applications, information sharing and communication platforms, software source etc.,) run compatibly with each other via Oss, and it is thereby essential to achieve integration among complex software structures (the average is ten software plus in a small institution). As a result of these complexities and vulnerabilities, the Government is willing to see a perfect fit through perceiving the stand-alone system as a Procrustean ICT Bed. Collaboration efforts between knowledge, technology and infrastructure, within human interactions, are complementary resources; however, is there a magic solution?

Most Ministries argued that, in 2012, one particular OS, which is capable of elementary working, does not fundamentally suffice for each institutional ICT infrastructure. To perform institutional services, without interruptions and free from problems, mutual dependencies (hardware \& software) are vital. Therefore, the Government wrongly perceived that it is essential to have all these technologies in a common language, and so the same technology platform gave an assurance of cohesiveness and completeness. In ICT infrastructure, changing the OS is the real threat for creating uncertainty in cohesiveness and completeness of all other components, so it is essential to plan all infrastructures at the beginning in terms of political, technical and institutional (including cost) dependencies. The difficulty/challenge is obvious, in particular, in large and crucial institutional networks. The Ministries wrongly believe that FOSS solutions will generate higher resource draining queries (time and cost consuming) than the currently available system and, in the migration process, the required efforts will result in disrupted and interrupted institutional routines and schemes; therefore, the risk cannot be taken by the Government. These are the reasons Ministries have given. The concept of managing ICT within institutions is challenging; however, can common language / the same technology platforms always promise ensuring cohesiveness and completeness in institutions? Or can commonality (without interoperability) only promise ensuing path dependency and lock-in? Nevertheless, technology emerges from various disciplines for various purposes, which are not inevitably in harmony. That concept is neglected from the reductionist approach taken by the Government.

The latest change is not only the One-Size-Fits-All-Software strategy. TUBITAK just declared that Turkey has developed a 'Real-Time Operating System' (RTOS) based on FOSS, which is available only in eleven advanced nations. The developed system is to complete unique and critical technology used for the national defence system. Hoverer, it is unclear whether RTOS is Pardus Fraud-Debian or not. The aim is to end external dependence, to be trusted within national secret projects and to create totally compatible system with other OSs ${ }^{45}$. Meanwhile, Turkey is also a part of 'International Symposium on Foundation of Open Source Intelligence and Security Informatics', which is to "provide a unique international forum for researchers, professionals, and industrial practitioners to socialize, seek collaboration, share and exchange their data, knowledge, and expertise." ${ }^{46}$

In the light of this information, it is clear that when the objective is perceived as an urgent issue for national defence \& security, FOSS is rigorously pursued as a real alternative; however, when the concept is to control/intervene in Microsoft dominant markets, the Government has not taken the liability to take the strategic initiative. What the Government in Turkey missed/neglected is that the digital security (cyber war) is not solely the concern of the government. There are several government and parliamentary reports directing how governments and ministries act in digital security and cyber wars; for example, how Ministry of National Defence, UYAP, MEBBIS, ILSIS were hacked. The history of cyber wars (since the first precedent between the USA and Iran) is crucially explained in the parliament as well ${ }^{47}$. Additionally, the 'Phishing Activity Trends Report

45 Scientific and Technological Research Council of Turkey (TUBITAK). TÜBİTAK'tan Savunma Sanayi'nde 'Yerli' İşletim Sistemi Devrimi, Retrieved 25/10/2013 from http://www.tubitak.gov.tr/tr/haber/tubitaktan-savunma-sanayinde-yerli-isletim-sistemi-devrimi-0

46 Scientific and Technological Research Council of Turkey (TUBITAK). Welcome to FOSINT-SI 201, Retrieved 25/10/2013 from http://uekae.tubitak.gov.tr/FOSINT-SI2012/

47 See, the report of 'Cyber Security and Cyber Wars' (Siber Guvenlik ve Siber Savaslar), presented in the Grand 
$2^{\text {nd }}$ Quarter 2012' by APWG ${ }^{48}$, stated that within the list of malware infected countries, Turkey is the sixth country, after South Korea, China and Taiwan, where 39,29\% of computers have already suffered a malware infection. Interestingly, the report stated that countries hosting the phishing sites list started with the USA at $58.45 \% \ldots$ and Turkey at $1.12 \%$ in April. These figures are perpetually changing, so they should be followed. The evidence indicates that the concern is not only the national-military security anymore, at least not in the future.

"At the heart of the debate there have been attempts to deepen and widen the concept of security from the level of the state to societies and individuals, and from military to non-military issues."(Krahmann, 2003, p. $.9^{49}$ )

These changes are understandable. The Government is willing to start research programs and strategies in various disciplines to raise Turkey to 'best practice' levels within its national potential and to meet national values and interests. However, is ICT effectively manageable in a national psyche? The literature indicates that it is. It is clear that these changes still cannot promise a precise 'National ICT Policy and Strategy' because FOSS is not carefully considered . Crucially, in Turkey, there is no compelling argument to attempt defining techno-political strategies on the argument of 'knowledge-based economy'. Over a decade ago, OECD $\left(1996^{50}\right)$ highlighted four knowledge(s) for current and future concepts: know-what ('facts'), know-why ('scientific knowledge of the principles and laws of natures'), know-how ('skills or the capability to do something') and know-who ('information about who knows what and who knows how to do', is the crucial concept). The question should be whether or not it is possible to conceptualise 'Commoditized National ICT Policy and Strategy' within global-technological structures and orders, without defining and addressing these four knowledge(s), and moving to the next steps. Nevertheless, identifying these four knowledge(s) is challenging in a digital era because software is digital goods which are 'bitstrings, sequences of $0 \mathrm{~s}$ and $1 s$,' differentiated from other goods with five features: 'nonrival', 'infinitely expansible', 'discrete', 'aspatial' and 'recombinant' (Quah, $2002^{51}$ ). There is no hallmark in ICT and societies. Importantly, there are know-that concepts, famously stated by Rumsfeld,

"There are no "knowns." There are things we know that we know. There are known unknowns. That is to say there are things that we now know we don't know. But there are also unknown unknowns. There are things we do not know we don't know."

In the long run, endurance and viability of 'National ICT Policy and Strategy' must be identified with the concepts of effectiveness, fairness and public accountability by techno-political interferences from the Government. So the question is why 'the best and the brightest policy making club' (think tank) does not interiorise/incorporate FOSS, and incorrectly forces one-sizefits-all systems with PCSS? It is because of (a) the incompleteness of ICT change, (b) path dependence, (c) institutional inertia, and arguably (d) corruption in NPM. As discussed above, public institutions have allowed themselves to become 'a lame duck' due to non-existent political interference. Perhaps that is the reason why there is no Government-shared compelling attention and argument to the future concepts; cloud computing \& political adequacy in ICT.

National Assembly of Turkey, on March 2012, Retrieved 25/10/2013 from http://www.tbmm.gov.tr/arastirma komisyonlari/bilisim internet/toplanti takvimi.htm.

48 APWG (2012). Phishing Activity Trends Report, $2^{\text {nd }}$ Quarter 2012; Unifying the Global Response To Cybercrime.

49 Krahmann, E. (2003). Conceptualizing Security Governance Cooperation and Conflict: Journal of the Nordic International Studies Association, Vol. 38(1): 5-26, Retrieved 25/10/2013 from http://dcafsp.tripod.com/readings/Security\%20Governance.pdf.

50 Organisation for Economic Co-operation and Development (OECD). (1996). The Knowledge-Based Economy, Paris; 1996, Retrieved 25/10/2013 from www.oecd.org/science/scienceandtechnologypolicy/1913021.pdf.

51 Quah, D. (2002). Digital Goods and New Economy, LSE Economics Department, Retrieved 25/10/2013 from http://econ.lse.ac.uk/staff/dquah/p/dp-0212hbne.pdf. 


\section{The Power of a National State, No Broken Promise}

As argued above, there are considered to be three legal and technical criteria, five legislative and seven administrative obstacles that make FOSS usage impracticable in public institutions. Importantly, there is no consideration for the hearing of FOSS and PCSS crucial distinctions in LAW. The Law is 'the weakest link'. So relevant questions are: Is there any tactical momentum in the law, regarding software precedents, with the exception of taxation and public procurement? Or is it more likely just a techno-privately oriented inclination in 'impassably heritaged' / centralist public institutions within the preference of PCSS friendly market sophistications for the purpose of squeezing self-motivate and self-interest markets (profit \& survival)?

In ICT, technical features and components are crucial but not the only factors in innovation and implementation of a particular technology in a particular national state. There are also many other social, political, economical and cultural factors, but it does not mean that all of these factors are equally effective. As Edwards \& Wajcman (2005 ${ }^{52}$ ) strongly argued, the statement of 'socially shaped' technology does ' $n o t$ ' mean to 'say' that characteristics and features of 'social definition' are 'equally effective'. The key points are 'politics' and 'negotiation' which define/confirm proximity and orientation of technological winning merits (originality, impact, practicality, measurability and applicability) in a particular society.

Institutional economics is inevitably political and it's focus mainly a junction between economy and law. For the purpose of this, a central national state forms and forces its own legalities to determine itself in the game of economic performances and behaviours to be the ruler of 'the game' in its 'society' (North, $1990^{53}$ ). We are in a world of 'knowledge-based economy' which is significantly different than 'traditional-based economy' (see, David Skyrme Associates, perhaps 'creative-based economy' in the future). Nevertheless, for ICT, the Government in Turkey has an embarrassing 'de facto Policy' (also called 'Informal Policy'). This de facto policy is seen as best option/practice recommendations, which are driven by a dominant position within publicly accepted and/or sectorally forced markets. Does de facto ICT policy promise to increase marketplace values (efficiency, interoperability and innovation)? That is an internationally controversial question.

It is clear that leading nations/governments cannot afford to not be a key player in the future, and it is obvious that the future is shaped by global corporations (e.g. Microsoft, Google, Apple, Samsung etc.). So, governments must have interactions/connections with global giant corporations. However, the crucial concept should be to follow or (ideally) to lead technological changes and innovations, not to purely answer and meet the current needs and requirements of a national state through dominant ICT suppliers (currently Microsoft in Turkey). The Government should perceive a birds-eye view of Turkey's capability instead of being dazzled by distinguishedlooking giant corporations' offers/freebies. The Turkey-ICT RTD Technological Audit Report $\left(2011^{54}\right)$ highlighted that "Turkey, in order not to lose ground, has to perform key efforts for successfully sustaining and improving her ground" (p.6) and "Turkey is performing under its potential" (p.8). Thus, there is a poor strategic plan in ICT. Nevertheless, it is still difficult to argue or conclude whether these complex interactions/connections are monopolistic or benign, but they are definitely strategic and momentous influencers.

The concept of 'Expendable 'Written' National ICT Policy' can be replicated in other leading and led national states because most nations have managed to move synchronously in ICT worldwide.

52 Edwards, P. and Wajcman, J. (2005). The Politics of Working Life, Oxford: Oxford University Press.

53 North, D.C. (1990). Institutional Change, and Economic Performance, Cambridge: Cambridge University Press

54 Pascall, S. (2001). Turkey- ICT RTD Technological Audit, European Commission, Information Society and Media, METU-TEKPOL, March, 2011, Retrieved 25/10/2013 from

http://stps.metu.edu.tr/sites/stps.metu.edu.tr/files/task9.pdf. 
Globally, some leading states have already taken initiatives to take over the PCSS realm in favour of FOSS (see, Government Open Source Policies Annual Report by the CSIS, 2010 55 ). However, some initiatives are arguably just a newspeak declaration. In reality and practice, they are not real (such as Turkey), e.g. currently the UK ICT policy (see, the report of an Open Source Strategy for Government by Cabinet Office in $2010^{56}$ ) is not only in favour of FOSS but also structures public institutions to take FOSS into consideration in the first instance. Such a policy appears to be both manipulating and controlling public software markets, instead of just monitoring them. Despite this declaration, there are some counter arguments between the UK ICT policy and the actual practices. For instance, Michael Gove, the Secretary of State for Education in England, sincerely and continually states their FOSS support in the media; however, the Department for Education have coincidently just had a new agreement with the Microsoft Corporation in 2012.

The study already diagnosed the conditions (omission/missing functionalities) behind the problem, but does not argue the best way to identify pervasive, trustworthy, flexible and transparent ICT polices in which FOSS and PCSS families are used. During the dynamic nature of ICT project management, consideration of evolving the unique characteristics of FOSS and PCSS should be made for the purpose of balancing FOSS and PCSS or, in the best scenario, taking over the PCSS realm in favour of FOSS. Valuable lessons might be highlighted from the global best practices. There is no universal truth, perception or advice for identifying the optimal level of ICT Policy in a national state, without taking into account each country's diverse realities. In this sense, all stakeholders' opinions, from national and international levels, within a socio-economic-political participatory network (interest groups' values and impacts, no forces from pressure group for synergy stemming building), should be all interlinked by a holistic vision to define a written ICT policy. So this is another research question that needs to be addressed carefully. Admittedly, societies do not change at the same speed as policy changes, and policy making does not always wait for the society to catch up. Thus, it is necessary to establish a real ICT policy, rather than declaring a 'speculative' or 'podium' policy. Is it possible?

According to Jessop $\left(2002^{57}\right)$, in 'governance, governance failure and meta-governance', there are four global dilemmas: 'Cooperation vs Competition', 'Openness vs Closure', 'Governability vs Flexibility' and 'Accountability vs Efficiency'. These dilemmas should be addressed globally. These conventional antagonisms (dilemmas) add another dimension to national ICT considerations. Even the concept of ICT 'Policy' is in a national state milieu, as the study argues, and the dimension is also multilevel and complex, and the powers are not clear or positioned. There are various actors (sphinx), who have influence on a national state, such as 'Special 301 Report', 'Digital Rights Management', 'Copy-Right', etc. For instance, the US Government publishes "Special 301 Report", which indicates countries where the patent licence rights are inadequate. The report is intended to put pressure on countries that made the list and leads to applying trade sanctions against these countries. Generally, China, Canada, Italy and Russia are accused of failing to take actions against internet piracy and counterfeit goods. However, the Special 301 Report is very controversial as regards to FOSS. There are many reports and articles, such as "Copyright lobby (IIPA) demands that USTR punish governments who 'consider' mandating open source software" (KEI, 2010 $0^{58}$ ), "Special 301 Report versus Free Software: Strong-arm tactics are the only way proprietary software can compete", "When using open source makes you an enemy of the state," and so on.

55 Center for Strategic \& International Studies (CSIS) (2010). The Government Open Source Policies Annual Report, Retrieved 25/10/2013 from http://csis.org/publication/government-open-source-policies.

56 Cabinet Office (2010). UK government ICT Strategy resources, Retrieved 25/10/2013 from https://www.gov.uk/government/publications/uk-government-ict-strategy-resources.

57 Jessop, B. (2002), 'Governance and Metagovernance: On Reflexivity, Requisite Variety, and Requisite Irony', the Department of Sociology, Lancaster University.

58 Knowledge Ecology International (KEI) (2010). Copyright lobby (IIPA) demands that USTR punish governments who 'consider' mandating open source software. 
Public and private services and market considerations and criteria influence understanding of a national policy at national and international levels, within fragmented networks, by many actors and factors. In this sense, the questions might be:

(a) How will the oligopoly of large suppliers act in the nationalised ICT policy? (b) Will they continue to monopolise their ICT provision? (c) How will leading national states (the USA, the UK, etc.) act in these complex relations?

These answers are not clear, but what is clear is that there are deliberate uncertainties created by 'imperfect markets' for economic gain. What is forgotten is that 'invention', 'innovation' and 'development' address different meanings. ICT is not a new phenomenon throughout modern history, but policy should be urgently rectified and differently addressed. That is the real challenge. It should cover all stakeholder perspectives and interests to make sure increasing marketplace values (efficiency, interoperability and innovation) are met. However, democratic powers in a national state have already shifted through using digital channels within participations of PublicPrivate-Partnerships, to an ambiguous space in which government bodies may not be welcome (unpowerful and unimportant). E.g. why are the Internet Treaty and Regulation and International Telecommunication Union (ITU), or PIPA, SOPA, ACTA and CISPA related arguments currently priority global concerns? If national states are welcome in a global network, it might be asked why there is still no international consensus about 'Interoperability' and, in particular, 'Software Interoperability Standards'. No agreement has been reached in a decade and it remains to be resolved in the future.

The above question leads us directly to 'globalisation'. It is crucial to underline how an understanding of globalisation can reveal an understanding of an individual nation state within the era of global change, especially the relationship between the nation state's power and its decisionmaking process. According to most globalisation theorists in the last few decades, an individual nation state has faced devolution of its power, its dependability and even its self-legitimisation. Although a variety of perceptions exist among theorists to explain this devolution, what they have in common are ongoing technological changes and their unprecedented influence upon the individual state and its society. Nowadays, the national state is seen as a 'borderless state' by Ohmae (1995), a 'powerless state' by Castells (1997), a 'hollow state' by Milward and Provan (2000) or, in a more moderate perspective, a partial state by Olssen et al. (2004) as,

\section{"The nation-state is "too small" to be entirely effective and "too large" to be entirely irrelevant" (ibid, p. $4^{59}$ ).}

It is clear that, for the national state, globalisation does not mean abandoning of the monopolisation power of the state. However, as the study argues that internal and external legitimacies in the state (it is also true on international level) are forced, pushed, lead or simply result in leaving and abandoning monopolisation power of the national state to international corporations regarding ICT, as

"The state is no longer the only regulator of market; we now have multiple forms of private regulation, and self-regulation. On the other hand, markets can no longer be (if they ever could) assumed to be either nationally based or nationally governed" (Dale \& Robertson, 2009, p.11960).

Although the nation state is not currently seen as the only decision maker, it must take

59 Olssen, M., Codd, J., and O’Neill, A., (2004). Education Policy: Globalization, Citizenship and Democracy. Thousand Oaks CA: Sage.

60 Dale, R. and Robertson, S. L. (2009). Capitalism, modernity and the future of education the new social contract, in T. Popkewitz and F. Rizvi (eds). Globalization and the Study of Education, Chicago, National Society for the Study of Education Yearbook, Volume 108, Number 2, 111-129. 
responsibility for controlling, manipulating and/or (at least) monitoring its own system and relative concepts, as suggested by Dale $\left(1997^{61}\right)$, despite the 'limits to state action'; 'the state does not 'go away'. What is interesting is that

"There is an important shift of emphasis involved (a new mix), but it is not an absolute break with or rupture from the previous state form; bureaucracies continue to be the vehicle for a great deal of state activity and the state does not hesitate to regulate or intervene, when it is able, when its interests or objectives are not being served" (Ball \& Junemann 2012, p.134 ${ }^{62}$ )

From this point of view, the national state dynamic changes and interventions from the Government are more like 'experimental', not 'definitive', as Jessop (2002) argued, and as in Turkey. 'A new hybrid form or mix of 'networks', 'bureaucracy' and 'market' 'in the shadow of hierarchy' exists to 'design policy ideas' in the national state (Ball \& Junemann, 2012, p.133). Therefore, ICT Policy, in particular, a Procrustean ICT Bed Strategy in the national state, should be globally understood as an 'experimental' strategy, not really 'definitive' perhaps for ongoing negotiations and positioning the national state within the global network because of evidently nationally prioritised values and interests from national cultural survival instincts for the future. Famously, Robert B. Reich foresaw as early as in 1991,

"We are living through a transformation that will rearrange the politics and economics of the coming century. There will be no more national products and technologies, no national corporations, no national industries. There will no longer be national economies. All that will remain rooted within national borders are the people who comprise the nation."

Although, there is no national 'product/idea' anymore, the national state has the responsibility to reduce squandered resources, to ensure the principle of separation of powers to eliminate vendor lock-ins (techno-politically supported (a) ICT 'legal monopoly' and (b) 'economic hegemony' towards PCSS) and to find the best way not to waste public money because

"Markets in fact generate inequality and encourage competition instead of cooperation as the central structuring norm of the community.... (The national state) must in their own right be regulated and controlled by the state" (Olssen et al., 2004, p. $176^{63}$ )

Nevertheless, efforts of 'politics' and 'negotiation' to define/confirm proximity and orientation of technological winning merits (originality, impact, practicality, measurability and applicability) in a particular society within global networks are so clear and identifiable, as to be controlled by the dominant ICT suppliers because of evident nationally prioritised concerns which are lobbied within an imperfect market, as Edwards \& Wajcman (2005) argued. The dynamic/dominant orientation of imperfect markets and inevitable failure of ICT's fate and ecosystems, within the centralist power illusion and status quo policy, lead to a state where there is no 'forgotten', or actually 'no broken promise' for ICT.

To support 'politics' and 'negotiation' concepts, the earlier examples are:

In 1984, in the scope of the Computer-Aided Education (CAE) project, the World Bank

61 Dale R. (1997). The State and Governance of Education: an analysis of the restructuring of the state-education relationship. in A. H. Halsey, et al. (Eds.) Education Culture, Economy, and Society. Oxford: Oxford University Press. Pp.273-282.

62 Ball, S.J. \& Junemann, C. (2012).Networks, New Governance and Education, Bristol: Policy Press.

63 Olssen, M., Codd, J., \& O'Neill, A., (2004). Education Policy: Globalization, Citizenship and Democracy. Thousand Oaks CA: Sage. 
distractingly suggested computer as a "tool to compensate for the poor quality and persistent deficiencies of suitable teachers" $\left(1993, \mathrm{p} .107^{64}\right)$. Even within current technology, is this suggestion plausible? Controversial!

On $23^{\text {rd }}$ January 2002, MP, Emre Kocaoglu asked the former Prime Minister about Microsoft Encarta CD-ROM Encyclopaedia and its associated website ${ }^{65}$. According to Kocaoglu, in the encyclopaedia and website, there was the Kurdistan map in eastern Turkey. After two years, the map was corrected. There were also similar complaints between Chinese and Taiwanese governments for Microsoft Encarta. According to McGraw-Hill $\left(2005^{66}\right)$, "Microsoft also bows to political pressure. The government of Turkey stopped distribution of an Encarta edition with the name Kurdistan on a map. Here Microsoft removed the name Kurdistan from the map. Governments frequently lobby the company to show their preferred boundaries on maps" (p.70). Additionally, there was a controversial Armenian issue, but unfortunately no formal proof was available.

There are mutual ongoing economical and political negotiations between the Microsoft Corporation and governments. It is not a new phenomenon. There are economical and political connections between national states where internationally argumentative issues exist, and international corporations which dynamically positioned themselves to take advantage of the issues to gain leverage. Although, the Microsoft Corporation claimed that Encarta Encyclopaedia had nine different versions to be certain that the Encyclopaedia did not cause any cultural clash, but, however, evidently comprehending local cultures through reflecting their histories might be perceived historically contradictory and politically conflicting, as in this case. Nevertheless, it is clear that the Microsoft Corporation used its power to mislead knowledge because of its own economic interests, and this drives the Government in Turkey. What is the consequence of this level of manipulation? Digital technology is currently everything, however, the power of a particular technology still remains with the country of technology's origin and headquarters location, in the USA in this instance. The Government in Turkey can only argue its point of view in Turkey because the raised issues are internationally controversial. Thus, political conflicts are strongly applied to the technology itself.

The latest examples are:

The Microsoft Corporation and a university in Turkey are currently in legal dispute over the use of pirated software. The Microsoft Corporation has not taken this kind of initiative for a long time in Turkey. Perhaps the Microsoft Corporation is testing its negotiation power with the Government to enable participation in the Fatih Project ( $\$ 8$ billion budget $\left.{ }^{67}\right)$. The Government previously has chosen the Android technology.

Additionally, an important example is from the discourse of Binali Yildirim, the Minister of the Ministry of Transport, Maritime Affairs and Communications, in the Open Academy Press Conference in January 2012. In the scope of the Fatih Project ${ }^{68}$,

64 World Bank (1993) Turkey: Informatics and Economic Modernization, a World Bank Country Study. The World Bank, Washington, D.C. Retrieved 25/10/2013 from http://www-

wds.worldbank.org/external/default/WDSContentServer/IW3P/IB/1993/03/01/000009265 3970128104047/Rendered/I NDEX/multiopage.txt

65 See, the parliamentary written question from MP, Emre Kocaoglu, Turkish Grand National Assembly (No.7/5728, 23 ${ }^{\text {rd }}$ January 2002 ), Retrieved 25/10/2013 from http://www2.tbmm.gov.tr/d21/7/7-5728s.pdf. The response to the question was published in the incoming paper due to not be answered. In other words, it was not going to be answered until the parliamentary question would be asked again.

66 McGraw-Hill. (2004). Evaluating a Company's External Environment, Retrieved 25/10/2013 from http://highered.mcgraw-hill.com/sites/dl/free/0070144478/617621/Cateora 03.pdf.

67 Google 'Yücel N. Microsoft'un Üniversitelerle Savaşı',

68 The Fatih Project is extremely complicated and controversial; therefore it is not included in the study. Nevertheless, all needed information is available / recorded on the internet. 
[Microsoft is the best known and the most common. There is no stop for the Microsoft Corporation. Two OSs will be in the system. A 'wanter' uses Microsoft; a 'wanter' uses Pardus-Linux which is such a thing developed by TUBITAK.

Question; in other words, various OSs will be used in 14 million tablets.

Minister: will be, it should be. In my notion, it is essential. Nevertheless, the MoNE is liable for that, so we need to confirm it from them. I acknowledge it as a warning. We will argue this issue with colleagues] ${ }^{69}$.

Additionally,

[Pardus-Linux OSs will be used in 400,000 Interactive Whiteboards (IWs) in schools in Turkey.]

(Practically for 'a wanter', it is impossible to use Pardus-Linux because there is not an external keyboard to select Pardus-Linux when IWs open through Windows Boot System. The power relationship is obvious.)

\section{Conclusion}

Techno-politically and optimistically speaking: We are currently paper-based societies (not a society) in a Digital-Era. Perhaps, in the short term future, we will be digital-based societies (not a society) in a Cyber-Era in the Century of 'Singularity' (no academic definition yet).

Many national states currently argue over what gun policies should be, for instance, in the USA. In ICT, technology is as a complex 'living organism' (more than a gun); it could be used for many purposes, so it is not a simple tool (perhaps never was and never will be): not only has it great power and provides a great potential, but it also puts forward its own lameness. The crucial point is that technology always claims how its own algorithm is perfect because there is no human bias, but the point is that humans use it. Technology evidently makes us more creative, but not necessarily smarter and/or more intelligent. Robertson (2008) emphasised that "knowledge is both a new problem and panacea for our time" $\left(\mathrm{p} .2^{70}\right)$. So, the concept is more than simple (gun) policies, but is the concept really nationally and internationally welcome? It is controversial!

While old aged, new is a street ahead. Too many arguments but not sufficiently detailed action (short/long term) plans and metrics,

still no milieu for 'Written' ICT Policies (obviously not a Policy).

In this paper, I first review the national ICT policy in Turkey through selecting the most appropriate and elite government documents to have a brief outline of the obstacles for the use of FOSS in public institutions, as well as a genetic perception of the Government views on FOSS that are driven by/ related to the concept of not governing 'National ICT Policy and Strategy'. To support this, I argue how FOSS is deliberately ignored in ICT projects due to obviously (a) institutional inertia, (b) path dependence, (c) ungovernable ICT changes, and, arguably, (d) corruption in new public management. I then attempted to investigate possible causal and dependency relationships of the currently established interlinks between the Government and unmanageable ICT changes to conclude that the Government has failed in making written ICT

69 ShiftDeleteNet. Fatih Projesi'nde Windows 8 de Olacak !; 2012, January 10, Retrieved 25/10/2013 from http://shiftdelete.net/fatih-projesinde-windows-8-de-olacak-34192.html.

70 Robertson, S.L. (2008) 'Producing' the Global Knowledge Economy: the World Bank, the KAM, Education and Development, in M. Simons, M. Olssen and M. Peters (eds) Re-reading Education Policies: Studying the Policy Agenda of the 21st Century, Rotterdam: Sense Publishers. 
Policies and in establishing pervasive and trustworthy (flexible) ICT ecosystems, which recognise either a balanced development between FOSS and PCSS or a FOSS favourable system.

In the second section, the evidence indicates that the Government has taken a de-facto ICT Policy by which Microsoft dominant markets control public institutions. Whilst techno-institutional lockins exist politically and are irreversible in Turkey, the future of Turkey's roadmap is mistakenly defined as a Procrustean ICT Bed Strategy from 'the best and the brightest policy making club' (think tank). This study finally makes arguments that the omission of ICT Policy in a national state is globally understood as an 'experimental strategy' (not really definitive), perhaps for ongoing negotiations and positioning a national state within a global network, due to evidently nationally prioritised values and interests. Perhaps it is not really a conclusive strategy (evidently not a policy). The dynamic and inevitable failure of ICT nature and ecosystems leads to state 'no broken promise' in ICT. As Samuel Beckett's famous quote says,

\section{"All of old. Nothing else ever. Ever tried. Ever failed. No matter. Try again. Fail} again. Fail better."

Nevertheless, this argument does not normalise/impair the failure/omission of promising an ICT policy. ICT projects have always an easily corrupted nature due to their complexity, therefore, corruption in ICT projects should be conceptualised through the four accepted knowledge(s) as the OECD report highlighted. In particular, know-who should be carefully addressed for leading us (as a citizen) to know how the Government gets it right and to trust information, avoiding corruption concerns. The final report of 'Information 2020 Challenges for the EU' by IDC comprehensively argued for know-who concept and finalised,

“... we are likely to move from an economy based on those - Too big to fail to one focused on servicing the needs of those - Too small to ignore" (2011, p.91 $\left.1^{71}\right)$

Thus, in answering the introductory question...

Is there a precise 'National ICT Policy in Public Institutions' in Turkey, in particular, an official recognition of the crucial distinction and subsequent evaluation between FOSS and PCSS? No and three times no!

\section{About the author:}

Hüseyin Tolu is a PhD student at University of Bristol in the United Kingdom. The article is a part of his PhD thesis which is 'The Productions of Techno-Politics of General Purpose Computing; Its Failures in a State and Education.' He has a particular interest in 'techno-cultural brokering' to conceptualise current and future technology in social practices. He can be contacted at ht7708@bristol.ac.uk or husevinalitolu@gmail.com or 00-44-7427157151.

Graduate School of Education, University of Bristol, Helen Wodehouse Building, 35 Berkeley Square, Clifton, Bristol BS8 1JA, UK.

71 See, European Commission, 'the EU Framework Programme for Research and Innovation', Retrieved 25/10/2013 from http://ec.europa.eu/research/horizon2020/index en.cfm?pg=h2020 


\section{Licence and Attribution}

This paper was published in the International Free and Open Source Software Law Review, Volume 5, Issue 2 (December 2013). It originally appeared online at http://www.ifosslr.org.

This article should be cited as follows:

Tolu, Hüseyin (2013) 'Expendable 'Written' ICT Policy in Digital Era, No Broken Promise', International Free and Open Source Software Law Review, 5(2), pp 79 - 104 DOI: 10.5033 /ifosslr.v5i2.86

Copyright (C) 2013 Hüseyin Tolu.

This article is licensed under a Creative Commons UK (England and Wales) 2.0 licence, no derivative works, attribution, CC-BY-ND available at http://creativecommons.org/licenses/by-nd/2.0/uk/

As a special exception, the author expressly permits faithful translations of the entire document into any language, provided that the resulting translation (which may include an attribution to the translator) is shared alike. This paragraph is part of the paper, and must be included when copying or translating the paper.

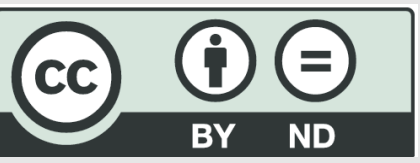

